\title{
Robustness of the Recent Global Atmospheric Reanalyses for Antarctic Near-Surface Wind Speed Climatology $\mathscr{O}$
}

\author{
Xu DONG AND YetANG WANG \\ College of Geography and Environment, Shandong Normal University, Jinan, China \\ SHugui Hou \\ Ministry of Education, Key Laboratory for Coast and Island Development, School of Geographic and Oceanographic \\ Sciences, Nanjing University, Nanjing, China \\ MINGHU DING \\ Institute of Tibetan Plateau and Polar Meteorology, Chinese Academy of Meteorological Sciences, Beijing, China \\ BAOLING YIN \\ College of Geography and Environment, Shandong Normal University, Jinan, China \\ YULUN ZHANG \\ Ministry of Education, Key Laboratory for Coast and Island Development, School of Geographic and Oceanographic \\ Sciences, Nanjing University, Nanjing, China
}

(Manuscript received 27 August 2019, in final form 6 February 2020)

\begin{abstract}
Near-surface wind speed observations from 30 manned meteorological stations and 26 automatic weather stations over the Antarctic Ice Sheet are used to examine the robustness of wind speed climatology in six recent global reanalysis products: the Modern-Era Retrospective Analysis for Research and Applications, version 2 (MERRA-2), the Japan Meteorological Agency 55-Year Reanalysis (JRA-55), the Climate Forecast System Reanalysis (CFSR), the National Centers for Environmental Prediction-U.S. Department of Energy (DOE) Reanalysis 2 (NCEP2), and the European Centre for Medium-Range Weather Forecasts (ECMWF) interim reanalysis (ERA-Interim) and fifth-generation reanalysis (ERA5). Their skills for representing near-surface wind speeds vary by season, with better performance in summer than in winter. At the regional scale, all reanalysis datasets perform more poorly for the magnitude, but better for their year-to-year changes in wind regimes in the escarpment than the coastal and plateau regions. By comparison, ERA5 has the best performance for the monthly averaged wind speed magnitude and the interannual variability of the near-surface wind speed from 1979 onward. Intercomparison exhibits high and significant correlations for annual and seasonal wind speed Antarctic-wide averages from different datasets during their overlapping timespans (1980-2018), despite some regional disagreements between the different reanalyses. Furthermore, all of the reanalyses show positive trends of the annual and summer wind speeds for the 1980-2018 period, which are linked with positive polarity of the southern annular mode.
\end{abstract}

Supplemental information related to this paper is available at the Journals Online website: https://doi.org/10.1175/JCLI-D-190648.s1.

Corresponding author: Yetang Wang, yetangwang@sdnu.edu.cn

\section{Introduction}

As one of the key components of the harsh environment of Antarctica, near-surface winds are among the strongest winds on Earth. The strong winds exert a noticeable impact on the redistribution of surface snow. 
Persistent winds cause considerable low-level sublimation of snowfall, which consequently results in $\sim 17 \%$ decrease of precipitation contribution to the Antarctic surface mass balance, and even up to $35 \%$ over the coastal regions of East Antarctica (Grazioli et al. 2017). As a result, $\sim 2.7 \%-6.6 \%$ surface of the Antarctic Ice Sheet has persistent negative net accumulation (Das et al. 2013). Observations and models have revealed that katabatic and föhn winds play an important role in surface melting on the Antarctic Ice Shelves through affecting near-surface temperature (e.g., King et al. 2017; Lenaerts et al. 2017; Turton et al. 2018). The Antarctic surface wind field has implications for the impact of the ice surface slopes on air radiational cooling, and the orographic adjustment of atmospheric circulations (Yasunari and Kodama 1993; Parish and Bromwich 2007). In addition, powerful winds are able to blow sea ice away from the Antarctic coasts and toward the open ocean, which helps to drive ocean overturning circulation (Abernathey et al. 2016). Therefore, the investigation of the Antarctic wind climate and variability is highly required. Despite substantial attempts to acquire near-surface wind observations, the observation data are still sparse, discontinuous, and irregularly distributed, especially in the interior of the continent, due to the logistical constraints under the extreme weather and climate conditions. Thus, estimating the wind changes at the continental scale based on observations is challenging. As a result, numerous Antarctic wind studies were at least partly dependent on global atmospheric reanalyses (e.g., Turner et al. 2009; Hazel and Stewart 2019; Yu and Zhong 2019), which provide temporally and spatially continuous representation of atmospheric state by means of numerical weather prediction models and data assimilation systems.

With the development of computational technology, enhanced data assimilation methods, and weather forecasting models, remarkable progress in the quality of the reanalysis datasets has been made in recent years. The corresponding global reanalysis products have been available for the public at present, such as the European Centre for Medium-Range Weather Forecast (ECMWF) interim reanalysis (ERA-Interim, herein ERAI), the Modern-Era Retrospective Analysis for Research and Applications, version 2 (MERRA-2), the Japan Meteorological Agency 55-Year Reanalysis (JRA-55), the Climate Forecast System Reanalysis (CFSR), the National Centers for Environmental Prediction-U. S. Department of Energy (DOE) Reanalysis 2 (NCEP2), and so on. In particular, the release of the fifth-generation climate reanalysis from the ECMWF (ERA5) has received wide interest. A number of improvements have been achieved in this new dataset, including higher spatial and temporal resolution, better representation of physical processes in the model, and significant increase in the amounts of historical observations used by the assimilation system, and it will eventually replace the ERAI reanalysis. Although the observations are assimilated, reanalysis products could contain uncertainties from various sources that are inherent in the forecast models, input data, and data assimilation, and spurious trends have been reported to appear in some reanalyses (e.g., Wang et al. 2016; Zhang et al. 2018; Huai et al. 2019). Furthermore, when generated, the different reanalyses used different observing and assimilation systems, and have different spatial and temporal resolutions. Therefore, it is essential to verify whether they do in fact represent the true state of the atmosphere before they are applied for Antarctic wind studies.

A number of studies have assessed the reliability of reanalyses for Antarctic wind climate on individual sites or specific regions. For example, Bracegirdle (2013) assessed the performance of six different reanalysis datasets for wind changes on the Amundsen Sea since 1979. Jones et al. (2016) provided an evaluation of the skill of four latest global reanalysis products for capturing near-surface wind speeds within the Amundsen Sea Embayment, West Antarctica. Validation of eight atmospheric reanalyses for wind variability in the Antarctic Peninsula has been performed by Nygård et al. (2016). Rodrigo et al. (2013) estimated the skills of ERA reanalyses and a regional climate model for representing surface wind climate at the ice sheet scale. It is still vital to make a comprehensive evaluation of the relative performance of the recently released reanalysis datasets for near-surface wind speeds over Antarctica. Additionally, the skill of the new ERA5 reanalysis for reproducing Antarctic nearsurface wind speed climate and changes is still unknown. Thus, the object of this study is to evaluate the reliability of near-surface wind speed climatology over Antarctic Ice Sheet in the six more recently released reanalysis products (i.e., ERA5, ERAI, MERRA-2, JRA-55, NCEP2, and CFSR) based on in situ wind speed observations.

\section{Data and methods}

\section{a. In situ observations}

Antarctic 10-m wind speed data are obtained from the Scientific Committee on Antarctic Research (SCAR) Reference Antarctic Data for Environmental Research (READER) project (Turner et al. 2004), which are freely available at https:/legacy.bas.ac.uk/met/READER/ data.html. Monthly mean wind speeds are calculated from 6-hourly synoptic data that are quality-controlled by removing erroneous and missing values caused by data 
transposition, problems of transmission on the Global Telecommunications System, anemometers freezing and screens covered by snow, variations of units, and so on (Turner et al. 2004). Physically anomalous wind speed data have been also manually discarded for each weather station (Turner et al. 2004). Monthly averaged values are regarded as missing data if daily observations in a month are not sufficient $(<90 \%)$ for the calculation of monthly mean. Wind speed observations from 30 manned meteorological stations since 1979 are used to correspond with the availability of the reanalysis products.

From 1980 onward, more than 100 automatic weather stations (AWSs) have been installed on the Antarctic Ice Sheet to offer continuous records of the basic meteorological parameters such as air temperature, wind speed, wind direction, relative humidity, and atmospheric pressure. However, suffering from the impact of the harsh environment on measurement instruments, few AWSs have continuous records longer than 15 years. The data are downloaded from the SCAR READER, and the Antarctic Meteorological Research Center (AMRC) and Automatic Weather Station (AWS) program. All AWS wind speed data also undergo rigorous quality filtering as do the manual weather station records (Turner et al. 2004). We only consider 26 AWSs with monthly averaged records covering at least 15 years, and monthly records are calculated when more than 25 days of observations are available for that month. The coordinates and lengths of records from each manned station and AWS are summarized in Table 1, and their spatial distributions are shown in Fig. 1.

\section{b. Reanalysis datasets}

The project of the ERAI is initiated to create a bridge between the previous atmospheric reanalysis, ERA-40 completed in 2002, and the next-generation reanalysis (ERA5), which is now available at ECMWF. ERAI spans from 1 January 1979 to 31 August 2019, and is generated using the ECMWF Integrated Forecast System, IFS (Cy31R2) (Dee et al. 2011). This dataset has a spatial resolution of approximately $79 \mathrm{~km}$ (T255 spectral truncation) on 60 vertical levels from the surface up to $0.1 \mathrm{hPa}$. A four-dimensional variational analysis (4D-Var) with a 12-hourly analysis window is applied for bias corrections. In each cycle, available observations are coupled with prior information from a forecast model to estimate the evolving state of the global atmosphere and its underlying surface (Dee et al. 2011).

ERA5 (Hersbach and Dee 2016) is the fifth generation of ECMWF global atmospheric reanalysis. The current ERA5 dataset spans from 1979 onward. The entire dataset will eventually extend back to 1950 . This reanalysis is produced by means of IFS Cy41R2, which includes a $62-\mathrm{km}$ resolution 10 -member $4 \mathrm{D}$-Var ensemble of data assimilation (EDA). The resolution of ERA5 is much higher than ERAI, with 137 hybrid sigma/pressure (model) levels in the vertical and a spatial resolution of $\sim 31 \mathrm{~km}$ in the horizontal. In addition to resolution, there are a lot of improvements upon ERAI. ERA5 yields information of the spatial and temporal variability in quality, better global balance of precipitation and evaporation, and more consistent sea surface temperature and sea ice. Moreover, tropospheric processes, tropical cyclones, precipitation over land in the deep tropics, and soil moisture are better captured (Hennermann and Guillory 2019).

MERRA-2 is the global atmospheric reanalysis produced by the NASA Global Modeling and Assimilation Office (GMAO), which is intended to replace the original MERRA product (MERRA-1) and reflects recent advances in atmospheric modeling and data assimilation. Its goals are to produce a regularly gridded, homogeneous record of the global atmosphere, spanning the satellite observing era from 1980 to the present. The GMAO/GEO-5 Data Assimilation System version 5.12.4 is used to produce this dataset. The variables of MERRA-2 are provided on a horizontal grid of $0.5^{\circ}$ latitude $\times 0.67^{\circ}$ longitude and on a vertical grid either at 72 hybrid-eta levels or 42 standard pressure levels between the surface and $0.01 \mathrm{hPa}$. Relative to the MERRA-1, MERRA-2 improves the assimilation of aerosol observations, better represents the stratosphere including ozone, makes bias corrections of aircraft observations, and reduces the imbalances (Gelaro et al. 2017). In particular, physical processes associated with ice and snow surfaces in polar regions are better represented (Gelaro et al. 2017).

JRA-55 (Kobayashi et al. 2015) is the second Japanese global atmospheric reanalysis conducted by the Japan Meteorological Agency (JMA), which is aimed to address the issues found in previous reanalyses and to produce a comprehensive atmospheric dataset suitable for studying multidecadal climate changes. The reanalysis dataset spans from 1958 to current. Compared to the previous-generation JMA reanalysis (JRA-25), JRA-55 uses a new radiation scheme and 4D-Var with a new variational bias correction for satellite data and several additional observational data sources. Its horizontal and vertical resolutions are $\sim 55 \mathrm{~km}$ (T319 spectral truncation) and 60 hybrid levels, respectively.

Version 1 of CFSR was implemented into operations at the NCEP covering the 1979-2010 period. It is designed as a global and high-resolution product to provide the best estimate of the state of the coupled system 
TABLE 1. Main characteristics of the 30 manned weather stations and 26 automatic weather stations (AWSs). The number of each station is presented in Fig. 1.

\begin{tabular}{|c|c|c|c|c|c|c|c|}
\hline No. & Name & Latitude $\left(^{\circ}\right)$ & Longitude $\left(^{\circ}\right)$ & Elevation (m) & Period & Manned/AWS & Class \\
\hline 1 & Gill & -80.0 & -178.6 & 30 & 1985-2018 & AWS & Coast \\
\hline 2 & Lettau & -82.5 & -174.4 & 55 & 1986-2018 & AWS & Coast \\
\hline 3 & Erin & -84.9 & -128.8 & 990 & $1996-2018$ & AWS & Escarpment \\
\hline 4 & Harry & -83.0 & -121.4 & 954 & 1994-2018 & AWS & Plateau \\
\hline 5 & Byrd & -80.0 & -119.4 & 1530 & 1980-2018 & AWS & Plateau \\
\hline 6 & Theresa & -84.6 & -115.8 & 1463 & 1994-2018 & AWS & Escarpment \\
\hline 7 & Rothera & -67.5 & -68.1 & 32 & 1979-2018 & Manned & Coast \\
\hline 8 & San_Martin & -68.1 & -67.1 & 4 & 1979-2018 & Manned & Coast \\
\hline 9 & Faraday & -65.4 & -64.4 & 11 & 1979-2018 & Manned & Coast \\
\hline 10 & Palmer & -64.3 & -64.0 & 8 & 1981-2018 & Manned & Coast \\
\hline 11 & Larsen_Ice_Shelf & -66.9 & -60.9 & 17 & 1985-2015 & AWS & Coast \\
\hline 12 & Butler_Island & -72.2 & -60.2 & 91 & 1986-2018 & AWS & Coast \\
\hline 13 & Arturo_Prat & -62.5 & -59.7 & 5 & 1983-2018 & Manned & Coast \\
\hline 14 & Great_Wall & -62.2 & -59.0 & 10 & $1985-2018$ & Manned & Coast \\
\hline 15 & Bellingshausen & -62.2 & -58.9 & 16 & 1979-2018 & Manned & Coast \\
\hline 16 & Marsh & -62.2 & -58.9 & 10 & 1979-2018 & Manned & Coast \\
\hline 17 & King_Sejong & -62.2 & -58.7 & 11 & 1988-2014 & Manned & Coast \\
\hline 18 & Jubany & -62.2 & -58.6 & 4 & 1988-2018 & Manned & Coast \\
\hline 19 & O_Higgins & -63.3 & -57.9 & 10 & 1983-2018 & Manned & Coast \\
\hline 20 & Esperanza & -63.4 & -57.0 & 13 & 1980-2018 & Manned & Coast \\
\hline 21 & Marambio & -64.2 & -56.7 & 198 & 1979-2018 & Manned & Coast \\
\hline 22 & Orcadas & -60.7 & -44.7 & 6 & 1979-2018 & Manned & Coast \\
\hline 23 & Belgrano_II & -77.9 & -34.6 & 256 & 1980-2018 & Manned & Coast \\
\hline 24 & Halley & -75.5 & -26.4 & 30 & 1979-2018 & Manned & Coast \\
\hline 25 & Neumayer & -70.7 & -8.4 & 50 & 1981-2018 & Manned & Coast \\
\hline 26 & Henry & -89.0 & -1.0 & 2754 & $1993-2017$ & AWS & Plateau \\
\hline 27 & Amundsen_Scott & -90.0 & 0.0 & 2835 & 1979-2018 & Manned & Plateau \\
\hline 28 & Novolazarevskaya & -70.8 & 11.8 & 119 & 1979-2018 & Manned & Coast \\
\hline 29 & Syowa & -69.0 & 39.6 & 21 & 1979-2018 & Manned & Coast \\
\hline 30 & Relay_Station & -74.0 & 43.1 & 3353 & $1995-2018$ & AWS & Plateau \\
\hline 31 & Molodeznaja & -67.7 & 45.9 & 40 & 1979-2018 & Manned & Coast \\
\hline 32 & Mawson & -67.6 & 62.9 & 16 & 1979-2018 & Manned & Coast \\
\hline 33 & Zhongshan & -69.4 & 76.4 & 18 & 1979-2018 & Manned & Coast \\
\hline 34 & Davis & -68.6 & 78.0 & 13 & 1979-2018 & Manned & Coast \\
\hline 35 & Nico & -89.0 & 89.7 & 3065 & 1993-2017 & AWS & Plateau \\
\hline 36 & Mirny & -66.5 & 93.0 & 30 & 1979-2018 & Manned & Coast \\
\hline 37 & Vostok & -78.5 & 106.9 & 3490 & 1979-2018 & Manned & Plateau \\
\hline 38 & Casey & -66.3 & 110.5 & 42 & 1979-2018 & Manned & Coast \\
\hline 39 & Dome_C_II & -75.1 & 123.4 & 3280 & 1996-2018 & AWS & Plateau \\
\hline 40 & D_47 & -67.4 & 138.7 & 1560 & 1983-2018 & AWS & Escarpment \\
\hline 41 & D_10 & -66.7 & 139.8 & 240 & 1980-2018 & AWS & Coast \\
\hline 42 & Dumont_Durville & -66.7 & 140.0 & 43 & 1979-2018 & Manned & Coast \\
\hline 43 & Priestley_Gl & -74.3 & 163.2 & 650 & 1987-2005 & AWS & Escarpment \\
\hline 44 & Tourmaline_Plateau & -74.1 & 163.4 & 1702 & 1990-2005 & AWS & Escarpment \\
\hline 45 & Marble Point & -77.4 & 163.7 & 120 & $1980-2018$ & AWS & Coast \\
\hline 46 & Manuela & -74.9 & 163.7 & 80 & 1984-2018 & AWS & Coast \\
\hline 47 & Mario_Zucchelli & -74.7 & 164.1 & 92 & $1988-2018$ & Manned & Coast \\
\hline 48 & Terra_Nova_Bay & -74.7 & 164.1 & 92 & 1988-2005 & AWS & Coast \\
\hline 49 & Marilyn & -80.0 & 165.1 & 75 & $1987-2018$ & AWS & Coast \\
\hline 50 & Pegasus_North & -77.9 & 166.5 & 20 & 1990-2017 & AWS & Coast \\
\hline 51 & Cape_King & -73.6 & 166.6 & 163 & 1987-2005 & AWS & Coast \\
\hline 52 & McMurdo & -77.9 & 166.7 & 24 & 1979-2018 & Manned & Coast \\
\hline 53 & Whitlock & -76.2 & 168.4 & 275 & $1983-2018$ & AWS & Coast \\
\hline 54 & Schwerdtfeger & -79.9 & 170.0 & 60 & $1985-2018$ & AWS & Coast \\
\hline 55 & Ferrell & -77.9 & 170.8 & 45 & 1981-2018 & AWS & Coast \\
\hline 56 & Elaine & -83.1 & 174.2 & 60 & 1986-2018 & AWS & Coast \\
\hline
\end{tabular}




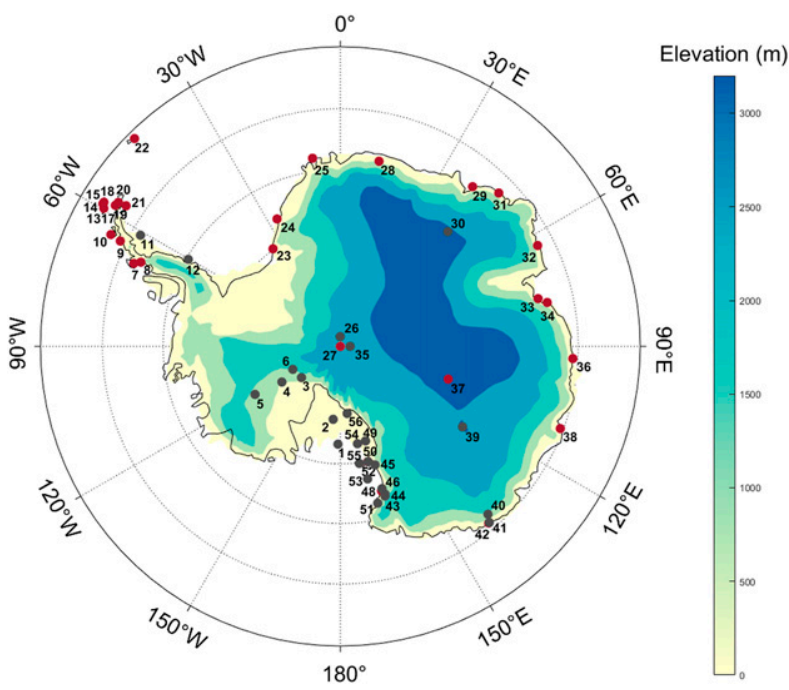

FIG. 1. Spatial distribution of 30 manned stations and 26 automatic weather stations.

with atmosphere, ocean, land surface, and sea ice over this period. Its successor, named CFSRv2, completed on 30 March 2011, is developed to improve consistency between the model states and the initial states produced by the data assimilation system (Saha et al. 2014). CFSRv2 covers between 2011 and the present. The spatial resolution of the CFSR is $\sim 38 \mathrm{~km}$ (T382 spectral truncation) and CFSR has 64 vertical levels with the highest level at $0.266 \mathrm{hPa}$.

NCEP2 is an updated global reanalysis and use an improved forecast model and data assimilation system to upgrade the parameterization of the physical process in surface flux fields, hydrological budget, shortwave radiation flux, and so on, on the NCEP-NCAR Reanalysis (NCEP1) to correct known errors in the NCEP1 (Kanamitsu et al. 2002). NCEP2 starts in 1979 and has the same resolution as the NCEP-NCAR reanalysis, with $\sim 210 \mathrm{~km}$ (T62) spatial resolution and 28 vertical sigma levels. The case of NCEP2 in this study is an exception since it has been released for quite some time and is close to a first-generation reanalysis product. Nonetheless, its skills for capturing nearsurface wind speeds over the whole of Antarctica have not been well investigated until now. Therefore, NCEP2 is also included in our estimate.

There are different approaches to calculate $10-\mathrm{m}$ wind speeds from the lowest model level in the different reanalyses. A modified Monin-Obhukhov routine is used to evaluate wind speed at $10 \mathrm{~m}$ in ERAI and ERA5 (https://www.ecmwf.int/sites/default/files/elibrary/2007/ 9221-part-iv-physical-processes.pdf). In MERRA-2, 10-m wind speeds are determined using the Helfand and Schubert scheme (Helfand and Schubert 1995), which includes the influence of a viscous sublayer for the transmission of heat and moisture over all surfaces with the exception of land (Molod et al. 2015). Assuming neutral stability of the lowermost model level, JRA-55 utilizes a univariate two-dimensional optimal interpolation to derive 10-m wind speeds (Torralba et al. 2017). For NCEP2, the 10-m wind speeds are extrapolated by Monin-Obukhov similarity functions using wind components at the first model level, combining with surface roughness length as well as the surface layer formulation (Pryor et al. 2009). As with NCEP2, CFSR uses the same method to calculate $10-\mathrm{m}$ wind speeds due to their common Noah land surface model (Saha et al. 2010).

In brief, the reanalysis products are different in many aspects. The assimilation methods of ERA5, ERAI, and JRA-55 are a 4D-Var scheme, whereas MERRA-2, CFSR, and NCEP2 use a 3D-Var data assimilation. Their horizontal resolutions range between $\sim 31 \mathrm{~km}$ for ERA5 and $\sim 210 \mathrm{~km}$ for NCEP2. The vertical resolutions range from 28 levels for NCEP2 to 137 levels for ERA5. The main features of the six reanalysis datasets used in this study (i.e., ERA5, ERAI, MERRA-2, JRA-55, CFSR, and NCEP2) are shown in Table 2.

The assimilation of observations for all reanalysis products includes radiosondes, satellite data, and some local observations. A key distinction of ERAI and ERA5 with other reanalyses is that they are also constrained by surface observations from land stations. However, all near-surface wind speed observations from

TABLE 2. Characteristics of reanalysis products used in this study.

\begin{tabular}{|c|c|c|c|c|c|c|c|}
\hline Reanalysis & $\begin{array}{l}\text { Horizontal } \\
\text { resolution }\end{array}$ & $\begin{array}{l}\text { Vertical } \\
\text { levels }\end{array}$ & $\begin{array}{l}\text { Assimilation } \\
\text { system }\end{array}$ & $\begin{array}{c}\text { Time } \\
\text { coverage }\end{array}$ & Organization & $\begin{array}{c}\text { Model } \\
\text { top } \\
(\mathrm{hPa})\end{array}$ & $\begin{array}{c}\text { Horizontal grid } \\
\text { of download data }\left({ }^{\circ}\right)\end{array}$ \\
\hline ERA5 & T639; 31 km & 137 & 4D-Var & 1979-2018 & ECMWF & 0.01 & $0.25 \times 0.25$ \\
\hline ERAI & $\mathrm{T} 255 ; \sim 79 \mathrm{~km}$ & 60 & 4D-Var & 1979-2018 & ECMWF & 0.1 & $0.75 \times 0.75$ \\
\hline MERRA-2 & $0.5^{\circ} \times 0.67^{\circ} ; \sim 55 \mathrm{~km}$ & 72 & 3D-Var & 1980-2018 & NASA/GMAO & 0.01 & $0.625 \times 0.5$ \\
\hline JRA-55 & $\mathrm{T} 319 ; \sim 55 \mathrm{~km}$ & 60 & 4D-Var & 1979-2018 & JMA & 0.1 & $0.562 \times 0.562$ \\
\hline CFSR & T382; 38 km & 64 & 3D-Var & 1979-2018 & NCEP & $\sim 0.27$ & $0.5 \times 0.5$ \\
\hline NCEP2 & $\mathrm{T} 62 ; \sim 210 \mathrm{~km}$ & 28 & 3D-Var & 1979-2018 & NCEP & $\sim 3$ & $1.875 \times 1.914$ \\
\hline
\end{tabular}




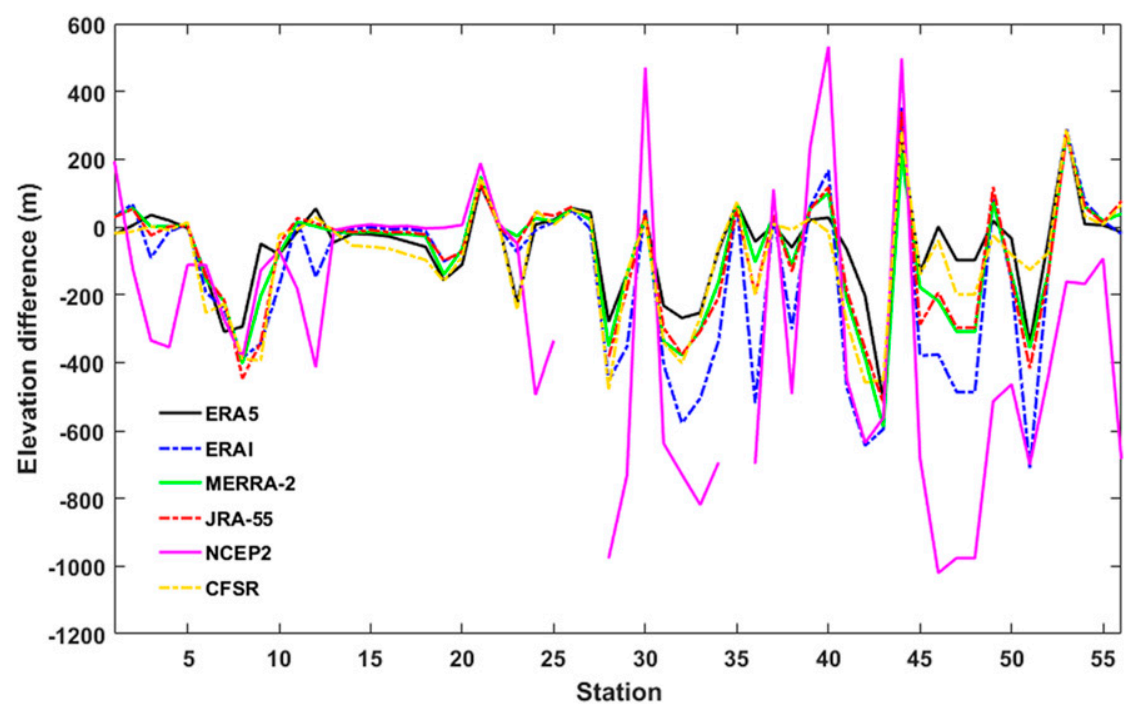

FIG. 2. Differences of elevation between in situ station locations and the corresponding reanalysis grid cells. The number of each station is the same as that shown in Table 1 .

land stations are not assimilated by ERAI (Dee et al. 2011) and ERA5 (Hersbach and Dee 2016). Also, other reanalyses do not assimilate wind speed measurements from weather stations and AWSs over Antarctica. Thus, the estimate of reanalyses based on wind speed observations is independent.

\section{c. Method}

Given that AWS measurements are nominally at $3 \mathrm{~m}$ above the surface (Lazzara et al. 2012), we extrapolate the wind speed observations to 10-m height based on a power-law wind profile assuming neutral atmospheric conditions (Paulson 1970; Sanz Rodrigo 2011).

As shown in Fig. 2, there is obvious difference of elevation between weather stations and the corresponding reanalysis grid cells in the reanalysis models. In general, the elevation biases are positive for the coastal stations, but negative for the interior of Antarctica. By comparison, ERA5 represents best the elevation of weather stations due to its high spatial resolution. NCEP2 with relatively coarse resolution demonstrates more positive elevation biases for the coastal sites and more negative biases in the inland elevations. The elevation biases in MERRA-2, JRA-55, and CFSR are very close for majority of weather stations. Here we do not make elevation corrections for the analyses.

Typical performance indicators including the correlation coefficient $(r)$, root-mean-square error (RMSE), and mean bias (MB) are used to quantify the differences of wind speeds between observations from 56 weather stations and simulations from the reanalysis products. They are calculated only for their overlapping periods.
Their significance is examined using the standard $t$ test. To understand the regional difference of uncertainties in wind speeds in the six reanalyses, the 56 weather stations are classified into three groups based on Antarctic geographic and climatic features, namely plateau, escarpment, and coast groups (Table 1). The plateau group has eight weather stations, locates in the interior of Antarctica with gently sloping terrain. Five stations are included in the escarpment group, where strong katabatic winds frequently happen. The coast group contains 43 weather stations, situated on the nearly flat ice shelves and next to the shore. Taking into account the climatic seasons in Antarctica (Périard and Pettré 1993), here seasonally averaged wind speeds are calculated throughout the year: December-February (summer), March-April (autumn), May-September (winter) and October-November (spring), respectively.

\section{Results}

\section{a. Performance for monthly wind speeds at the continent scale}

Continental performance of the reanalyses, derived from simply averaging results of the single observation locations, likely biases toward the regions with high data density such as the Antarctic Peninsula and Ross Ice Shelf, due to the unequal distribution of observations. To reduce the possible biases, we use the averaged records for the data-rich regions, combining with other records at the data-sparse regions to generate the final Antarctic estimate. Figure 3 shows the seasonal cycle of the performances of the six reanalysis datasets, which 

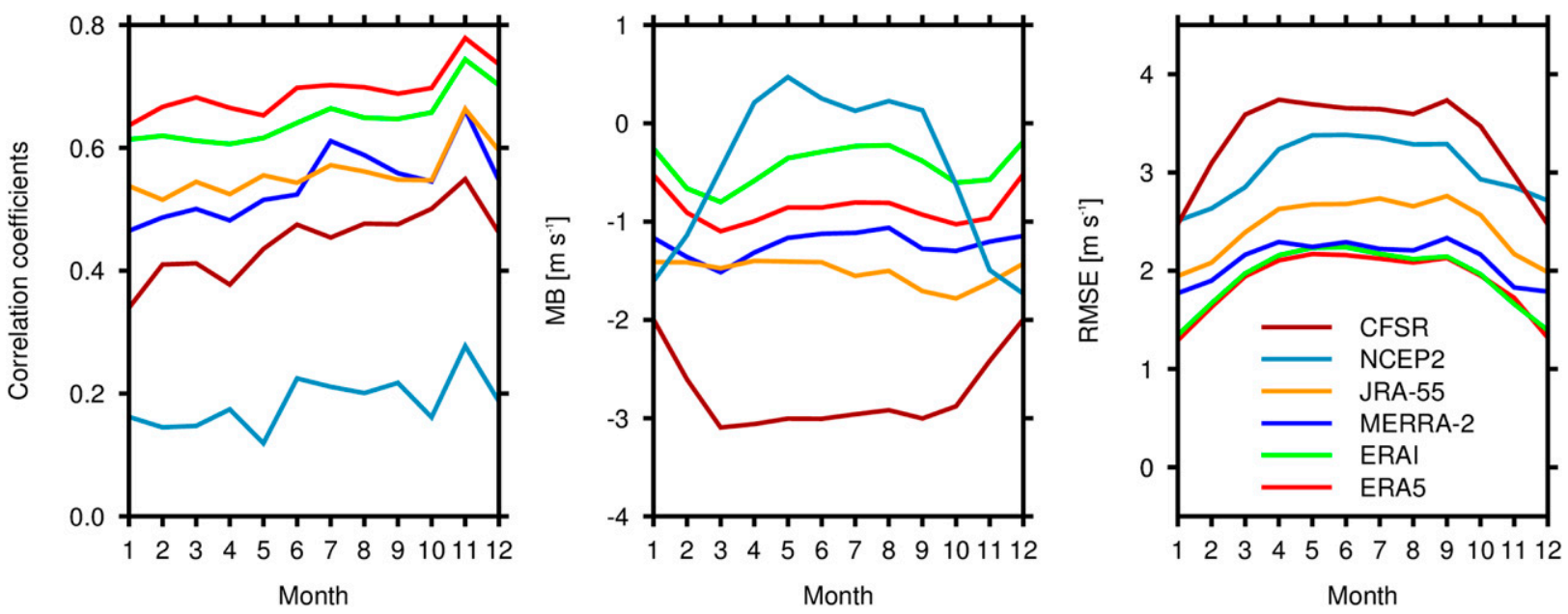

FIG. 3. Averaged monthly correlation coefficients $(r)$, root-mean-square error (RMSE), and mean bias (MB) of six reanalyses with respect to surface wind speed observations from weather stations at the ice sheet scale. We use all available data after 1979.

are determined by the $r$, RMSE, and MB. Among these reanalyses, ERA5 presents the highest correlations for any month, with $r$ values of $>0.6(p<0.01)$ for all the months except January, whereas the lowest correlations are found in the NCEP2, and all $r$ values are $<0.3$. Although poorer than ERA5, the correlations between ERAI and in situ observations are still relatively high for any month, whose $r$ values are $>0.6$. The correlations of JRA-55 are similar with MERRA-2, and both are slightly higher than CFSR, but lower than ERAI and ERA5.

In terms of the RMSE, all datasets exhibit a clear seasonal dependence, with high values in winter and low ones in summer. ERA5 has the lowest RMSE, and RMSE of ERAI is slightly higher than ERA5. The performances of MERRA-2, NCEP2, and CFSR are as good for the summer months, but dramatically different from each other on winter months. Based on RMSE of the analysis products, the skill of ERA5 for capturing monthly wind speeds in magnitude ranks first, and ERAI's skill is second, followed by MERRA-2 and then JRA-55. CFSR and NCEP2 perform worse than the other datasets, especially for winter months.

For NCEP2, MB values in winter months are positive, but negative during the summer months. At any month, highly negative MB in CFSR suggests that the mean near-surface wind speeds are greatly underestimated by CFSR, with all MB values $<-2 \mathrm{~m} \mathrm{~s}^{-1}$. ERAI, ERA5, MERAA-2, and JRA-55 also show negative MB at any month. In comparison, ERAI has the best performance, with mean biases in magnitude for all months $<1 \mathrm{~m} \mathrm{~s}^{-1}$, smaller than any other datasets.

Differences in the correlations and bias among the reanalysis products may be associated with their skills for capturing the lower atmospheric stratification. The resolution of the reanalysis also contributes to their performance. NCEP2 with lowest resolution presents the lowest correlations. To summarize, among these reanalysis products, ERA5 has the smallest RMSE and thus is in best agreement with monthly averaged wind speed observations. Despite the slightly higher MB of ERA5, relative to ERAI, the highest correlations are found in ERA5, suggesting that interannual variability of observed wind speeds are best represented by this reanalysis.

\section{b. Reanalysis performance at regional scales}

Considerable differences appear in the performance of the six reanalyses for annual and seasonal mean wind speeds over the plateau, escarpment, and coastal regions (Table 3). Whenever for annual and seasonal mean observations, all reanalysis products except for NCEP2 and JRA-55 exhibit higher correlations at the escarpment than the other regions. Despite high correlations, the highest RMSE $\left(>3 \mathrm{~m} \mathrm{~s}^{-1}\right)$ are observed over the escarpment for all reanalyses at any season. In relation to annual and seasonal mean wind speed observations, ERAI performs best over the coastal and plateau regions, but MERRA-2 has the highest performance for the escarpment zone. RMSE of ERA5 are slightly higher than ERAI for any region.

Although ERA5, ERAI, MERRA-2, JRA-55, and CFSR have negative MB for both seasonal and annual wind speeds on the ice sheet scale, notable MB differences exist among the six datasets at the regional scale. ERA5 and ERAI present negative MB in escarpment and coastal regions, but positive in the plateau for all seasons except for spring. However, there is no obvious 


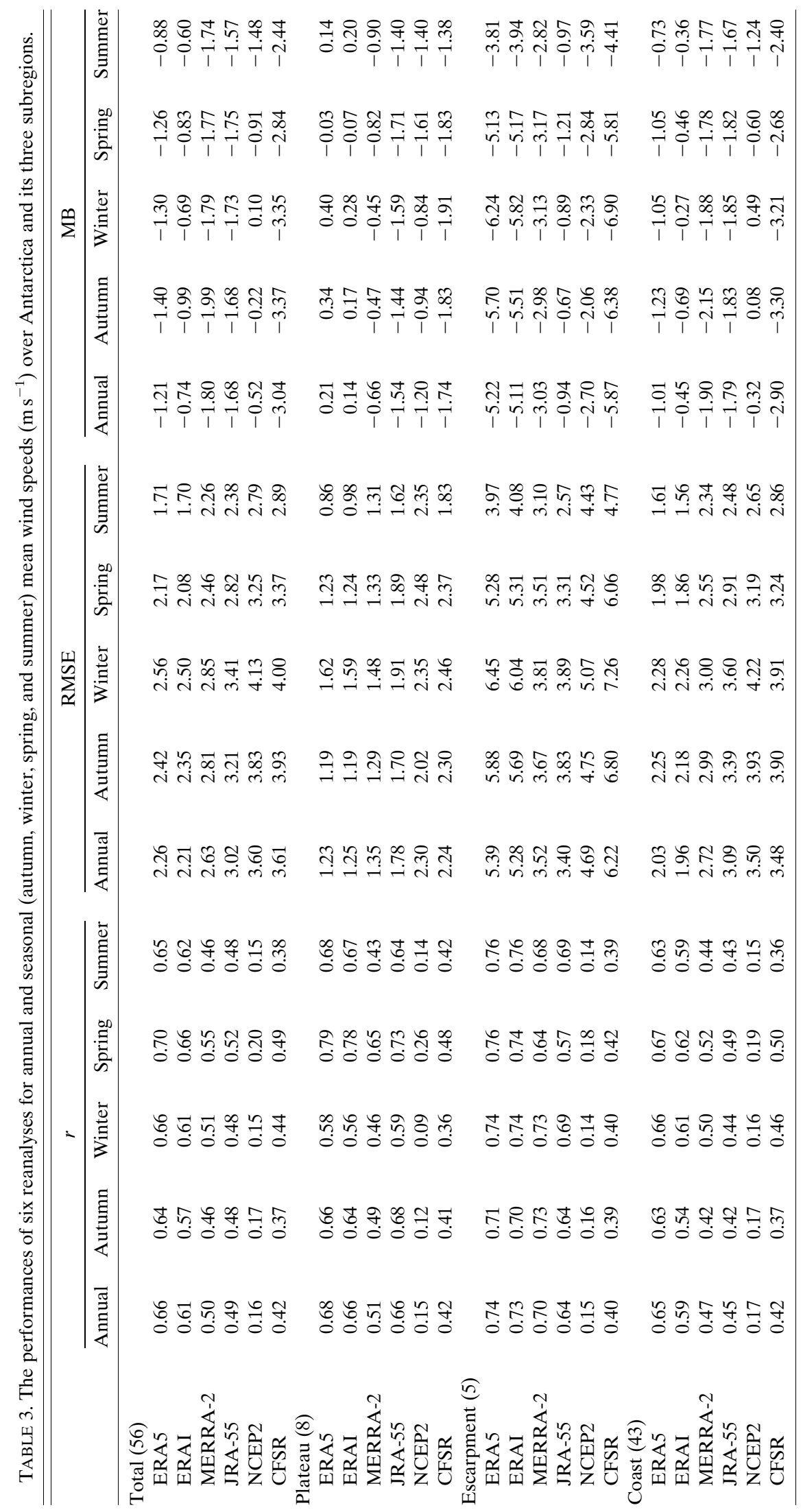



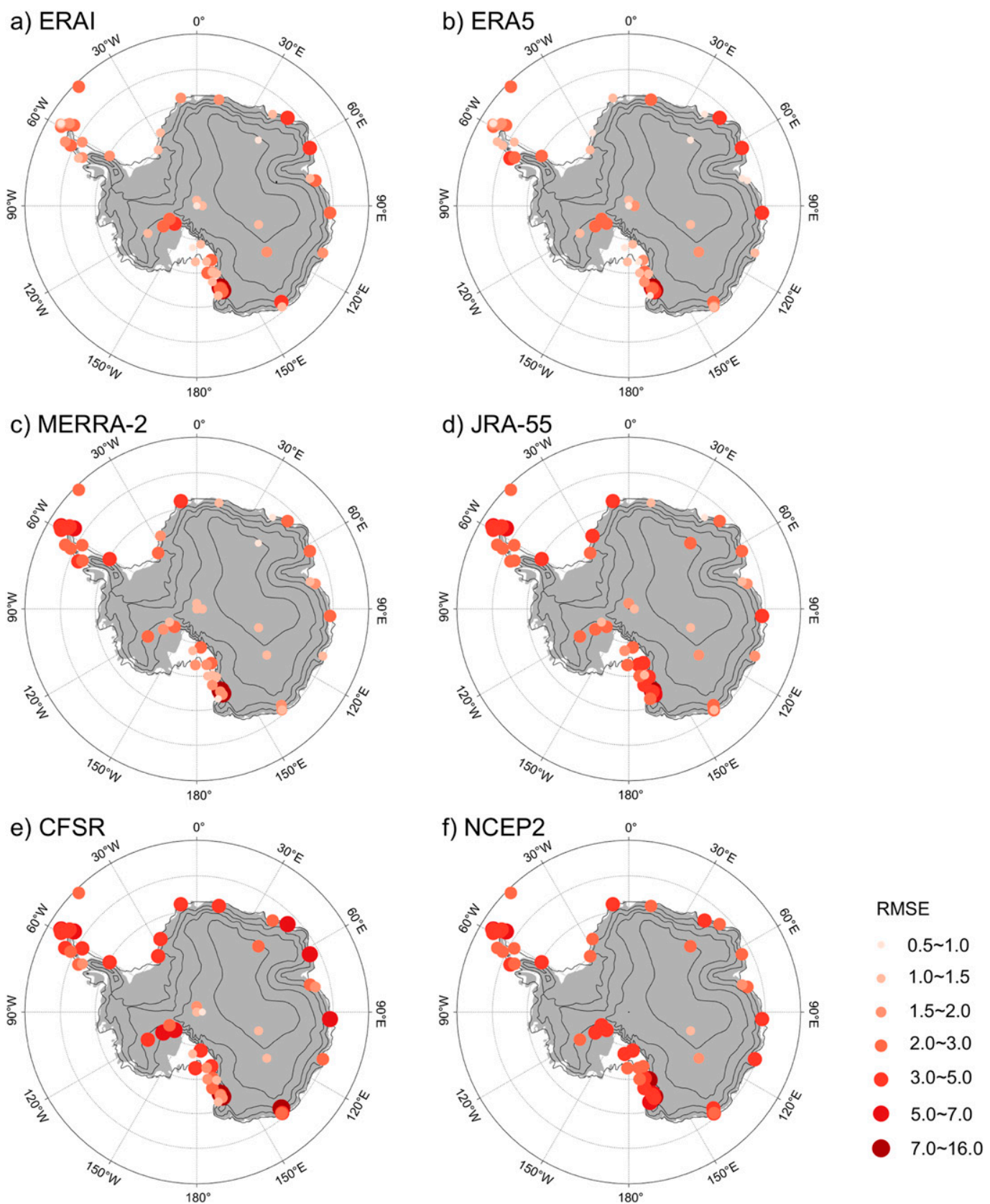

FIG. 4. Root-mean-square error (RMSE) of annual surface wind speed simulations in the six reanalysis datasets, relative to wind speed observations.

regional difference in NCEP2. For any subregions, MB of seasonal and annual wind speeds in MERRA-2, CFSR, and JRA-55 are negative. In general, MB in ERA5 are higher than ERAI for the three subregions.

Similar to the whole of Antarctica, the performances of all six reanalysis products in the three subregions are seasonally dependent, with lower MB and RMSE in summer and higher in winter. Despite the seasonal dependence in RMSE and MB, the seasonal variations in the $r$ values are much less evident for each reanalysis. Among the datasets, ERA5 presents the highest correlations with time series of observed near-surface wind speeds over the three subregions.

Spatial distribution of the RMSE of annual mean wind speed simulations from the six reanalyses, relative to in situ observations, are shown in Fig. 4. Large RMSE largely occur in escarpment and coastal areas with complex topography. In particular, the weather stations 
a) ERAI
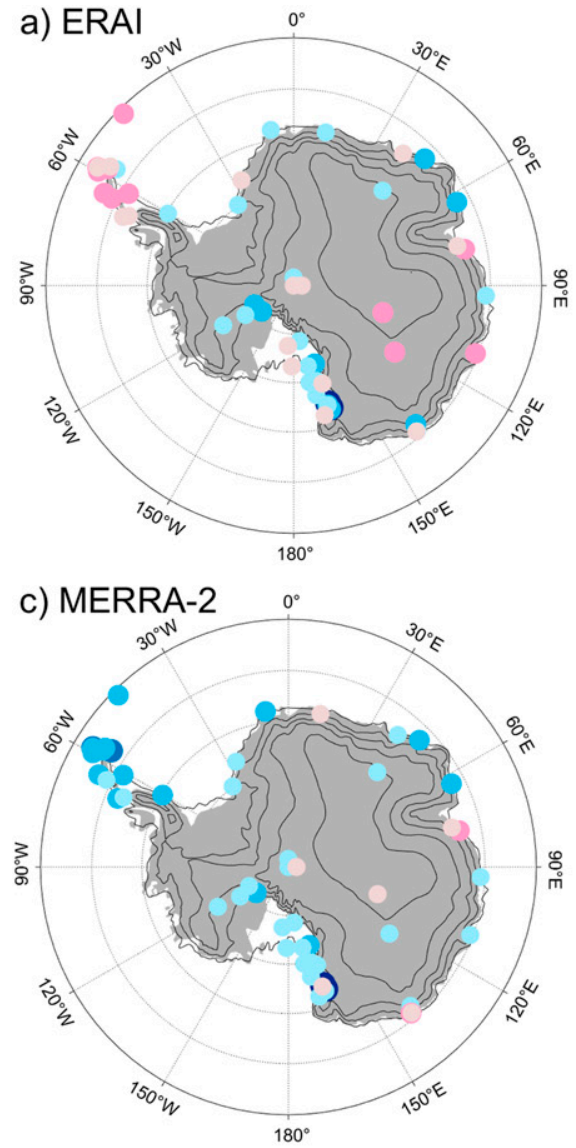

e) CFSR

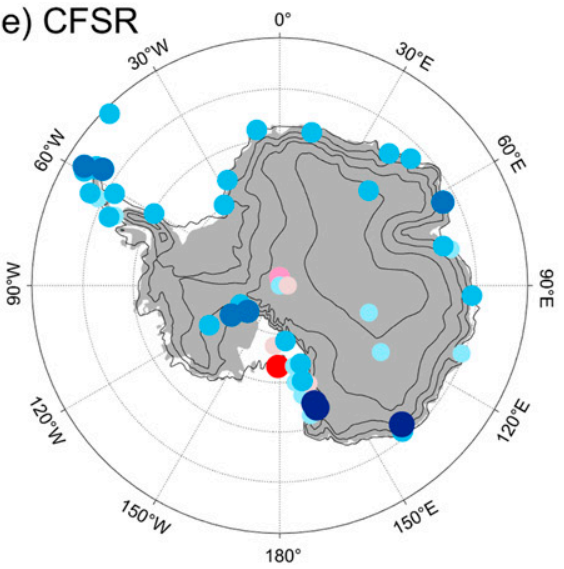

b) ERA5

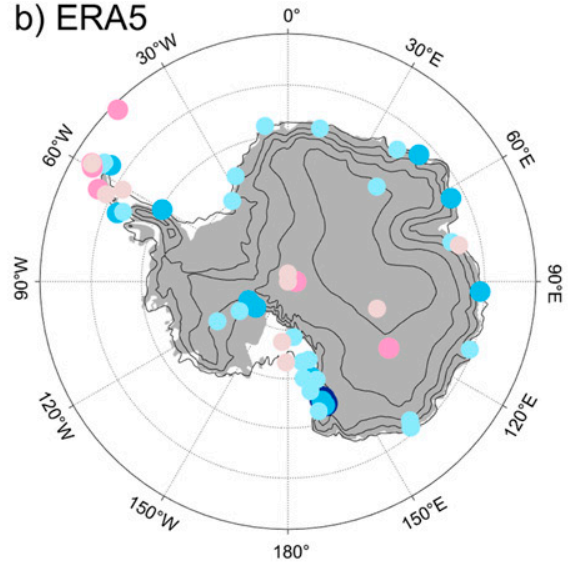

d) JRA-55
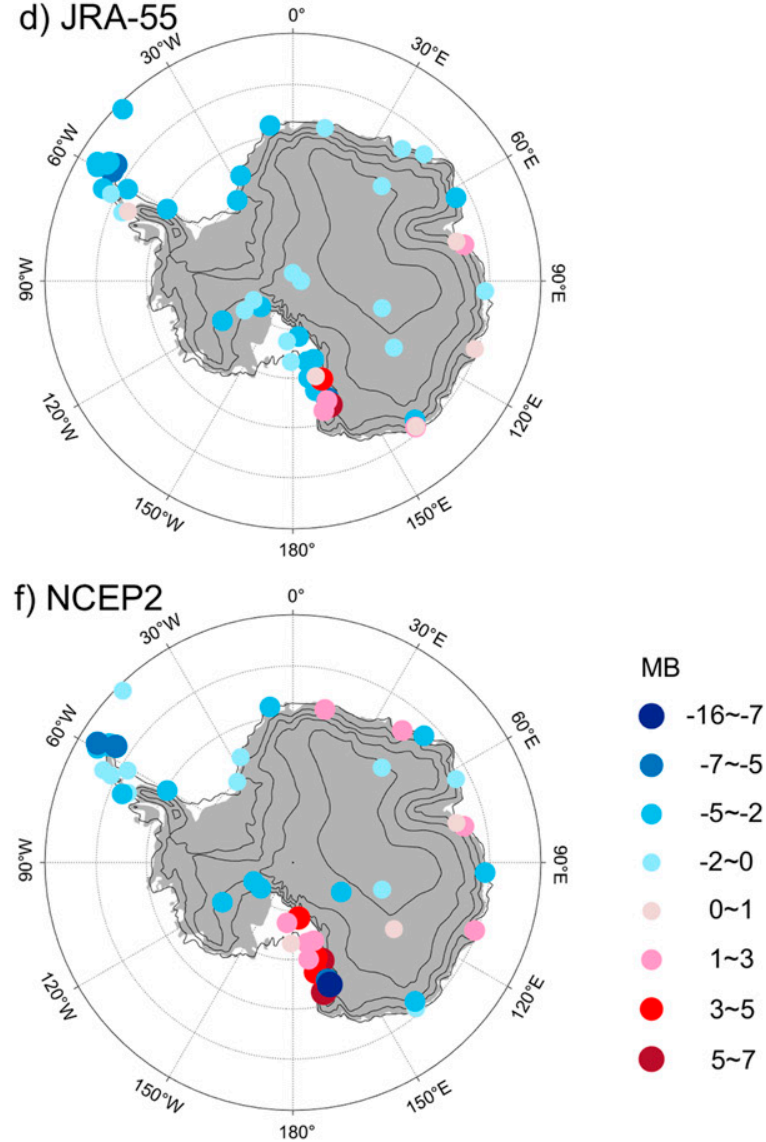

FIG. 5. As in Fig. 4, but for the mean bias (MB).

located in Victoria Land have the largest RMSE. RMSE in the Antarctic Peninsula are also larger than in the interior of the continent, partly due to a higher wind variability. Contrary to that, RMSE is generally low on some stations of East Antarctic Plateau and Ross Ice Shelf where the terrain is smooth.

Visible differences are identified in the spatial patterns of the $\mathrm{MB}$ among the six reanalysis datasets
(Fig. 5). MERRA-2, JRA-55, and CFSR tend to underestimate the near-surface wind speeds at the overwhelming majority of sites. An obviously dipole pattern of MB can be seen in NCEP2, with underestimation at the West Antarctic inland sites and the Antarctic Peninsula, and overestimation at the western coastal sites along the Ross Sea. Similar to ERAI, ERA5 shows the wind speed overestimation at East Antarctic Plateau 


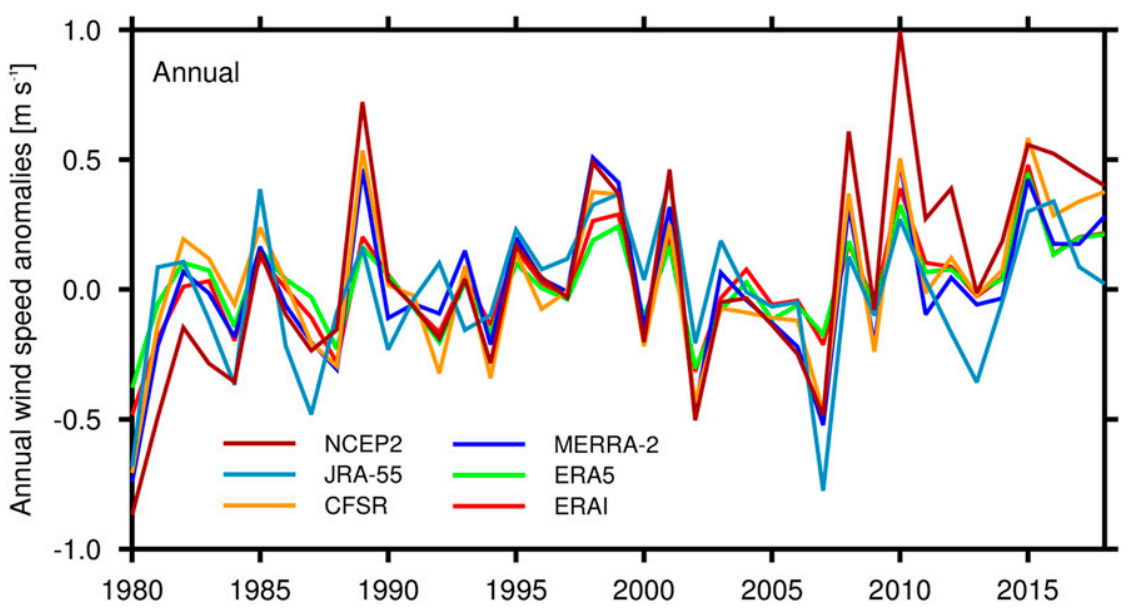

FIG. 6. Time series of annual mean surface wind speed anomalies with respect to their respective 1981-2010 means, averaged over Antarctica $\left(60^{\circ}-90^{\circ} \mathrm{S}\right)$.

sites, whereas underestimation occurs at the escarpment sites and most coastal sites.

\section{c. Intercomparison of the reanalysis products}

Figures 6 and 7 present the time series of annual and seasonal mean near-surface wind speed anomalies, averaged over Antarctica $\left(60^{\circ}-90^{\circ} \mathrm{S}\right)$, for their common period 1980-2018, respectively. Time series of annual and seasonal mean wind speeds from these six datasets exhibit robust correlations, with $r$ values in the range of
$0.83-0.98$, suggesting the broad consistency of their interannual variability. In spite of the consistence, some differences occur among the datasets. NCEP2 shows a conspicuous upward trend in the annual mean, especially in the summer mean wind speeds between 1980 and 2018, which is not found in the other datasets. For both annual and seasonal means, the interannual fluctuations in NCEP2 are larger than other reanalysis products. Despite slightly lower interannual variability than NCEP2, JRA-55 shows larger year-to-year
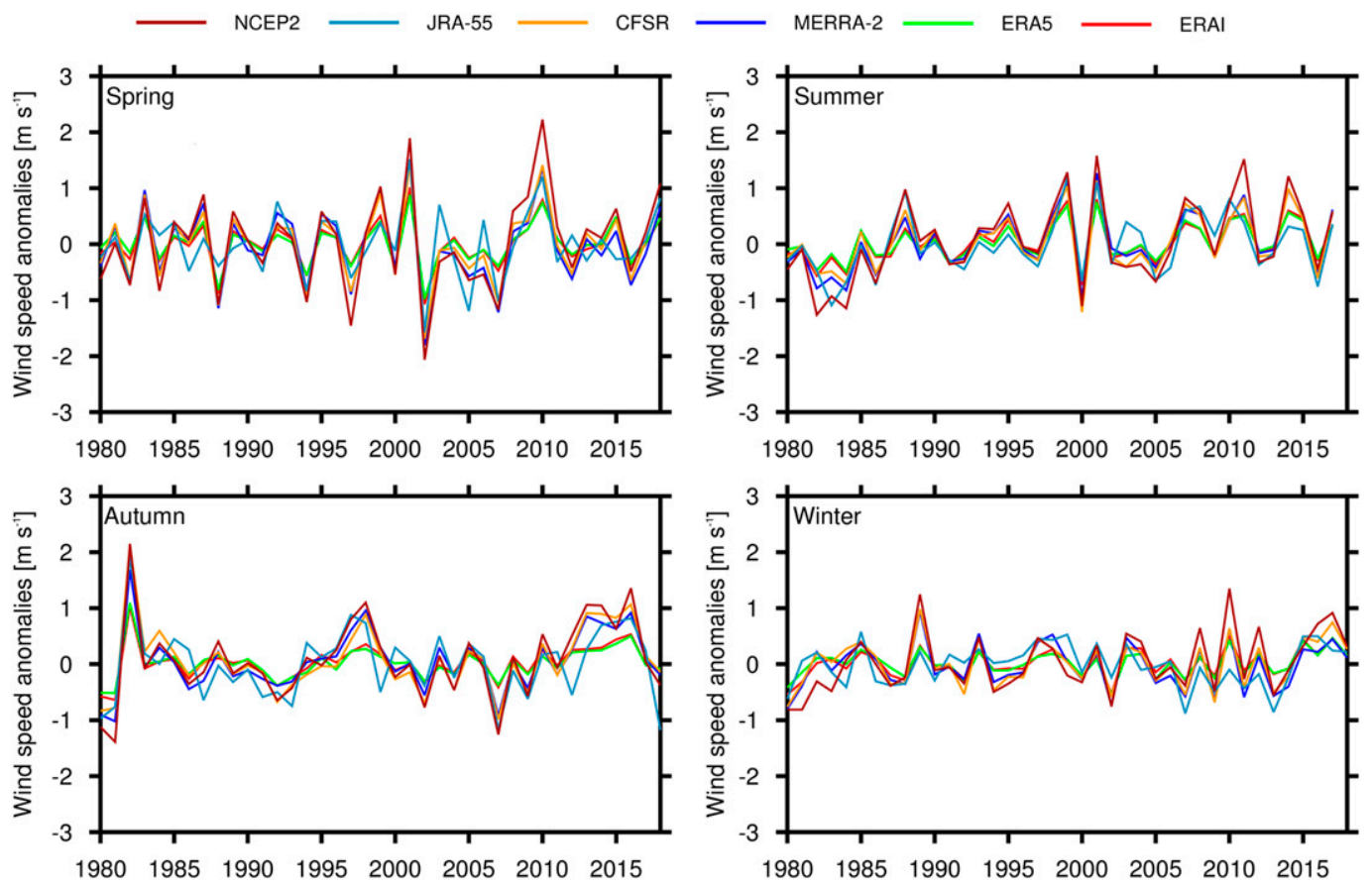

FIG. 7. Time series of seasonal mean surface wind speed anomalies with respect to their respective 1981-2010 means, averaged over Antarctica $\left(60^{\circ}-90^{\circ} \mathrm{S}\right)$. 
TABLE 4. Trends in annual and seasonal near-surface wind speeds $\left(\mathrm{m} \mathrm{s}^{-1}\right.$ decade $\left.^{-1}\right)$ from the six reanalyses for the 1981-2018 period, averaged over Antarctica $\left(60^{\circ}-90^{\circ} \mathrm{S}\right)$. The bold fonts show that trends are significant at the $95 \%$ confidence level.

\begin{tabular}{|c|c|c|c|c|c|}
\hline Datasets & Annual & Summer & Autumn & Winter & Spring \\
\hline ERA5 & $0.06 \pm 0.02$ & $0.11 \pm 0.05$ & $0.04 \pm 0.04$ & $0.04 \pm 0.03$ & $0.02 \pm 0.05$ \\
\hline ERAI & $0.08 \pm 0.02$ & $0.12 \pm 0.05$ & $0.07 \pm 0.04$ & $\mathbf{0 . 0 7} \pm \mathbf{0 . 0 3}$ & $0.03 \pm 0.06$ \\
\hline MERRA-2 & $0.07 \pm 0.04$ & $0.19 \pm 0.07$ & $0.11 \pm 0.08$ & $0.01 \pm 0.06$ & $-0.02 \pm 0.1$ \\
\hline JRA-55 & $0.05 \pm 0.04$ & $0.14 \pm 0.08$ & $0.03 \pm 0.09$ & $0.01 \pm 0.05$ & $0.03 \pm 0.09$ \\
\hline NCEP2 & $0.18 \pm 0.05$ & $0.24 \pm 0.10$ & $0.13 \pm 0.10$ & $0.17 \pm 0.07$ & $0.13 \pm 0.12$ \\
\hline CFSR & $0.08 \pm 0.04$ & $0.14 \pm 0.08$ & $0.07 \pm 0.09$ & $0.05 \pm 0.06$ & $0.04 \pm 0.10$ \\
\hline
\end{tabular}

variations than ERAI, ERA-5, MERRA-2, and CFSR for the 2000-18 period.

Linear trends in the time series of annual and seasonal mean near-surface wind speeds from the six reanalysis datasets over Antarctica during 1980-2018 are shown in Table 4. The prominent feature is that all datasets present the positive trends in the annual and seasonal wind speeds with the exception of MERRA-2 for spring wind speeds, regardless of their statistical significance. Furthermore, it is common for all reanalyses that the trends are larger in summer than other seasons. For the whole 39-yr period, among the reanalysis products, NCEP2 exhibits the largest trends for both annual and seasonal wind speeds. In JRA-55, trends of annual and seasonal wind speeds are not statistically significant at the confidence level of $95 \%(p>0.05)$. In spring and autumn, trends are also not statistically significant $(p>$ $0.05)$ for all datasets.

To further investigate spatial differences in the temporal trends in the near-surface wind speeds over Antarctica, we calculate linear trends in annual mean wind speed fields of the six reanalyses from 1980 to 2018 (Fig. 8). Considerable disagreement between different reanalyses is found in the spatial extent and magnitude of their trends. NCEP2 reveals significantly large and positive trends on the majority of grids over Antarctica with values of $>0.2 \mathrm{~m} \mathrm{~s}^{-1} \mathrm{decade}^{-1}$. Similarly, for CFSR, significantly positive trends are dominant over the Antarctic Ice Sheet; the negative trends only occur over limited parts of the coastal Antarctica, Antarctic Peninsula, and the Transantarctic Mountains. Smaller and less significant trends are found in JRA-55, compared with the other datasets. Significant and positive trends are present in most regions of the East Antarctic Plateau in ERAI, ERA5, CFSR, MERRA-2, and NCEP2, but not in JRA-55. In spite of the substantial differences, some similar trend patterns can be found in the several datasets. Spatial patterns of ERAI trends are similar with ERA5. For ERAI, ERA5, and MERRA-2, negative trends occur over the central Antarctic Peninsula and Ross Sea coasts, but positive over the coasts of $35^{\circ}-100^{\circ} \mathrm{E}$ sector. Over the coastal Victoria Land, negative trends are common for ERAI, ERA5,
MERRA-2, and JRA-55. However, the trends for the four reanalysis datasets are positive over the plateau of Dronning Maud Land.

In respective reanalysis datasets, the spatial extent of trends in the averaged wind speeds at the $95 \%$ significance level differ among the seasons (Figs. S1-S4 in the online supplemental material). All datasets reveal smaller and less significant trends in autumn than the other seasons. Differences in trend signs over some regions also exist in the different seasons. Negative trends occur in summer for all datasets over the coast regions of $90^{\circ}-120^{\circ} \mathrm{W}$ sector, which are not observed in other three seasons. For NCEP2, large and negative trends along the coasts of West Antarctica only occur in summer. In ERAI and ERA5, negative trends are present in autumn over East Antarctic Plateau, but not in other three seasons. MERRA-2 shows significant positive trends over the coast regions of $75^{\circ}-110^{\circ} \mathrm{E}$ sector for all seasons with the exception of summer. In spite of these difference, spatial patterns in the trends of the wind speeds averaged over summer, winter, and spring are basically consistent with those of annual mean.

\section{Discussion}

All reanalyses generally show negative biases in annual and seasonal averaged wind speeds, relative to the observations at the weather stations and AWSs. In particular, the biases are more negative in the escarpment or coastal regions, where local enhancement of winds could be observed (King and Turner 2007). The local steep orography channels the surface flow and generates high surface wind speeds in katabatic confluence zones. However, all reanalysis products probably fail to represent orographic and katabatic forcing, and thus lead to significant biases (King and Turner 2007; Parish and Cassano 2003; Rodrigo et al. 2013; Tetzner et al. 2019). Despite the large biases, high correlations are found with wind speed observations. This may be attributable to extremely steep terrain which urges winds flowing downslope following a constant direction and thus results in the development of stable wind 
a) ERAI

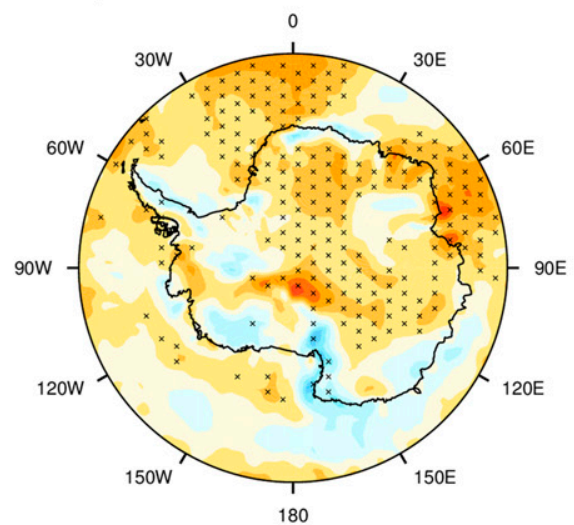

c) MERRA-2

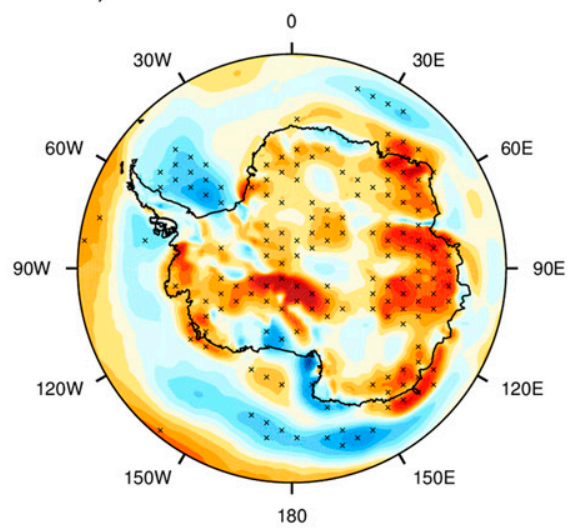

e) CFSR

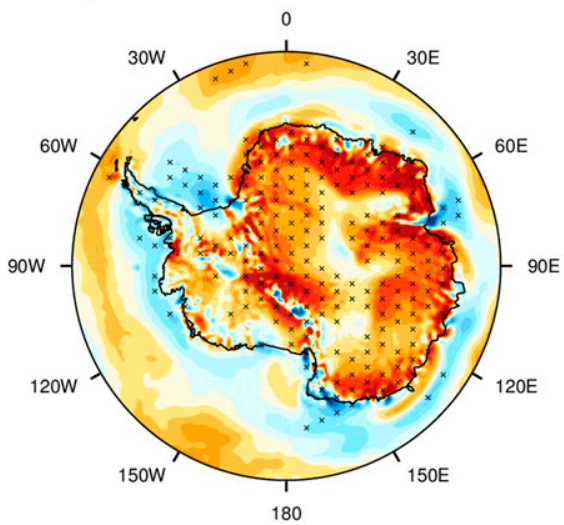

b) ERA5

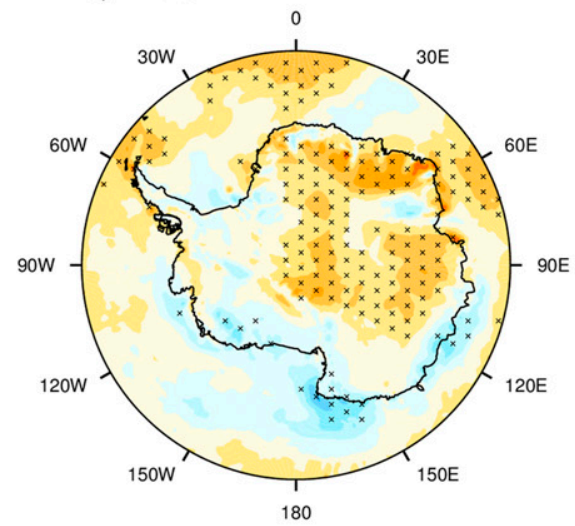

d) JRA-55

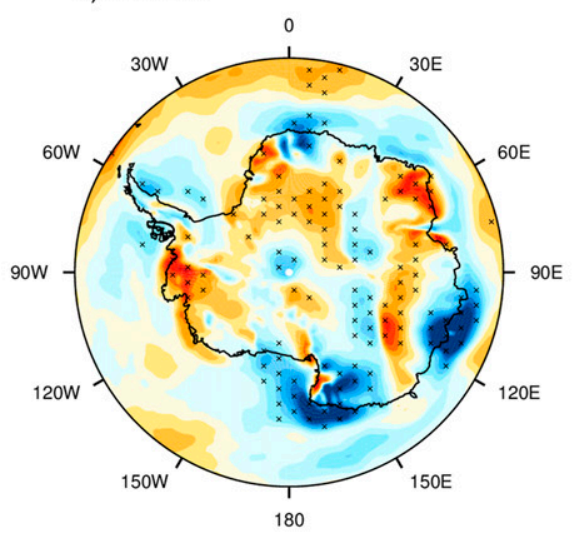

f) NCEP2

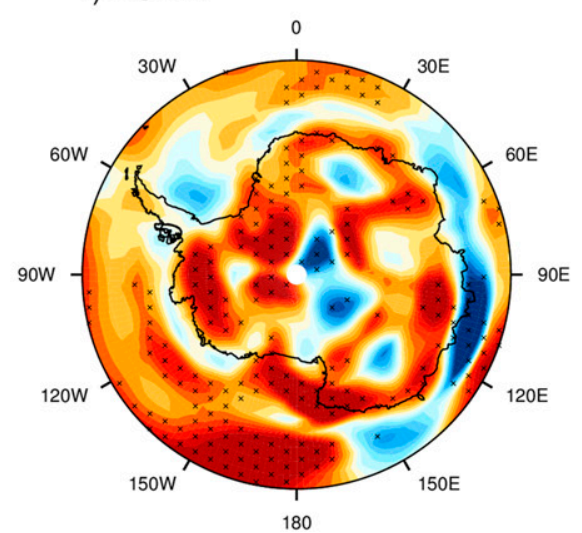

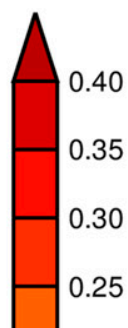

0.20

0.15

0.10

0.05

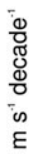

$-0.10$

$-0.15$

$-0.20$

$-0.25$

$-0.30$

$-0.35$

$-0.40$

FIG. 8. Linear trends in the mean annual near-surface wind speeds $\left(\mathrm{m} \mathrm{s}^{-1}\right.$ decade $\left.^{-1}\right)$ from the six reanalysis datasets. Crossed regions show that the trends are significant at the $95 \%$ confidence level.

conditions over time. The global reanalyses are prone to present relatively higher skills for representing the lower temporal variability in wind speed and stable wind conditions (Rodrigo et al. 2013).

It is common for the six reanalysis products that their performances for near-surface wind speeds to show an obvious seasonal dependence, with high RMSE in winter months, and low RMSE in summer months. In summer, Antarctic winds are largely driven by the largescale pressure gradients (van den Broeke and van Lipzig 2003). In winter, the katabatic effects are most pronounced. These reanalysis products usually have relatively good skills for capturing large-scale pressure (Bracegirdle and Marshall 2012), but not for katabatic 

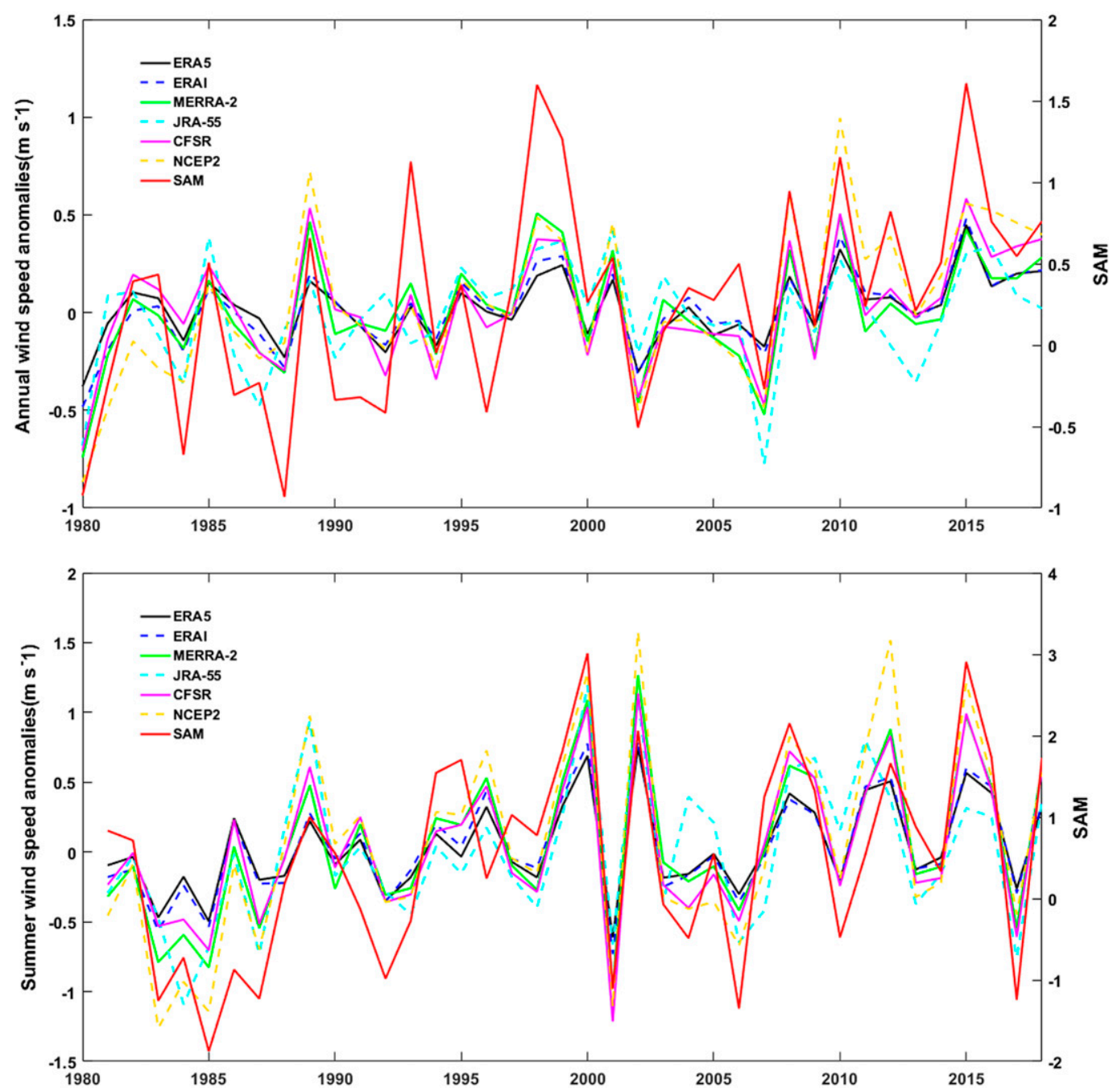

FIG. 9. The time series of annual and summer mean near-surface wind speed anomalies in the reanalyses and the SAM indices by Marshall (2003) for the 1980-2018 period.

effects as described above. This is a possible explanation for the seasonal dependence of the performance of the reanalysis for wind speeds.

The time series of annual mean near-surface Antarctic wind speeds in the six reanalysis products show a consistent positive trend during 1980-2018, with the largest trend during the summer (Table 4), despite quantitative difference from one reanalysis to another. Furthermore, the most robust performance of ERA5 is found for the interannual variability in annual and seasonal mean wind speeds. These imply that annual and summer wind speeds over Antarctica experience positive trends for the 1980-2018 period. The southern annular mode (SAM) has shifted toward positive phases since the mid1970s, and the positive phases are most prominent in summer (Marshall 2003). The positive polarity of SAM means a high pressure over the midlatitudes and low pressure toward the high latitudes of the South Hemisphere. As a consequence, a positive SAM usually causes the enhancement of poleward-shifted westerly wind, and increases wind speeds (Thompson and Solomon 2002). The annual and summer mean nearsurface wind speed anomalies in the reanalyses are correlated highly and significantly with the observationbased SAM indices, respectively (Fig. 9). Thus, the positive annual and summer trends may be related to the strengthening of positive polarity of SAM from the mid1970s onward.

As shown in Figs. 6 and 7, time series of wind speeds from all reanalyses averaged over Antarctica are more consistent over 1999-2018 relative to 1979-98, which could be explained by changes in the amount and quality of assimilated observations over time, affecting the data used for the bias correction, and thus leading to biases in 
the wind speeds (Long et al. 2017; Torralba et al. 2017). The Television and Infrared Observation Satellite (TIROS) Operational Vertical Sounder (TOVS) operated during 1978-98 has few and broader channels than the Advanced TIROS Operational Vertical Sounder (ATOVS) starting in May 1998. In addition, since the late 1990s, more satellite instrument observations are assimilated into the reanalyses.

The skills for representing near-surface wind speeds vary by the different global reanalysis datasets at the regional scale. No single reanalysis is superior to the others for capturing near-surface wind speeds at all subregions. JRA-55 does the best job for the escarpment region, whereas the best performance is seen in ERAI for the coastal area, and ERA5 in the plateau region. A possible source of the discrepancy is the different approaches to determine $10-\mathrm{m}$ wind speeds from the lowest model level in the different reanalyses, as reported by Torralba et al. (2017). The different routines of the boundary layer parameterization and varying assimilated observing system in each model may also be responsible for the discrepancies among the trends. Furthermore, the scale differences (different grid resolutions) of representing elevation and surface roughness in the six reanalyses to some extent affect the accuracy of wind speeds derived from these datasets. However, this influence cannot be distinguished from the other factors affecting the uncertainties in different reanalyses. To address this, future studies are required to perform different sensitivity experiments by modifying spatial resolution of a reanalysis.

The elevation probably affects how well orographically influenced flow is captured by reanalysis, and thus elevation difference between reanalyses and observations may be an important source of uncertainties in the wind speed simulations. There are no significant relationships between elevation difference and $\mathrm{MB}$ of wind speeds at the sites of weather stations in any reanalysis (Fig. S5). Although the performances of all reanalyses are generally better for inland Antarctica (Figs. 3 and 4) where elevation differences are small (Fig. S6), the picture is different for the coastal regions. For any reanalysis, the locations with large elevation difference do not certainly exhibit large biases. For example, in ERAI, large elevation differences $(>400 \mathrm{~m})$ are found at eight locations in the $10^{\circ}-120^{\circ} \mathrm{E}$ sector of the ice sheet margins (Fig. S6b). However, wind speed biases at four locations are small, with RMSE values of $<2 \mathrm{~m} \mathrm{~s}^{-1}$ (Fig. 4). Therefore, the influence of elevation difference is complicated, and it is also challenging to quantify the extent to which the biases are attributed to elevation difference.

It is noticeable that the assumption of a constant elevation of the AWS above the surface and stable neutral atmosphere may result in partial disagreement between observations and reanalysis simulations. A decrease in the height of the wind measurement instruments due to snow accumulation might slightly reduce the magnitude of the winds from the AWSs, and thus the vertical wind profile should be adjusted by considering the height changes.

\section{Conclusions}

In this study, the reliability of near-surface wind speed climatology over Antarctica from six more recently released reanalysis products (i.e., ERA5, ERAI, MERRA-2, JRA-55, CFSR, and NCEP2) are evaluated using 30 manned stations and 26 automatic weather stations, based on three statistical quantities: $r, \mathrm{MB}$, and RMSE.

The representation of near-surface wind speeds in all six reanalysis products depends on seasonality, with low performance in winter and high performance in summer. By comparison, among the datasets, ERAI has the smallest mean bias in magnitude whose values for all months are extremely small $\left(<1 \mathrm{~m} \mathrm{~s}^{-1}\right)$. However, ERA5 performs best for the monthly averaged wind speeds, with the lowest RMSE at any month. Furthermore, the highest correlations with the time series of observations are observed for ERA5, suggesting that the interannual variability of the near-surface wind speed during 1979-2018 is best represented by the newly produced reanalysis. These results are very useful for the studies of Antarctic wind speed changes, and also for Antarctic sea ice modeling because they are usually applied for the determination of the surface wind stress affecting ice dynamics, especially if we take into account that ERA5 will extend back to 1950. However, for the examination of trends, we think that a multireanalysis approach is probably a better choice, because spurious trends in the different reanalyses can offset each other.

Intercomparison reveals the robust agreements of interannual variability in the seasonal and annual mean wind speeds over the entire Antarctica for the 1980-2018 period among the six reanalysis datasets. This seems to imply the comparable skills of capturing the large-scale circulation driving wind changes over the high latitudes of the Southern Hemisphere among the datasets. Moreover, all reanalysis products show a common signal of increased trends in annual and summer Antarctic wind speeds since 1980. The strengthening of wind speeds is associated with the enhanced positive polarity of SAM from the 1970s onward. However, differences occur in the magnitude of the Antarctic-wide mean trends (Table 4 ) and spatial changes in trends (Fig. 8 and Figs. S1-S4 in the online supplemental material) during the same period. For example, NCEP2 reveals most strong trends in the annual and 
summer and winter wind speeds averaged over all of Antarctica. Large areas with highly significant positive trends over Antarctic mainland occur in the CFSR and NCEP2, but not in the other datasets.

Acknowledgments. This work was supported by the Outstanding Youth Fund of Shandong Provincial Universities (ZR2016JL030), the National Natural Science Foundation of China (41971081 and 41576182), the Project for Outstanding Youth Innovation Team in the Universities of Shandong Province (2019KJH011), and the Strategic Priority Research Program of the Chinese Academy of Sciences (XAD19070103). Thanks to the three anonymous reviewers for their constructive comments and suggestions to improve this paper.

Data availability statement. Monthly $10-\mathrm{m}$ wind speed records at the weather stations are downloaded from http://legacy.bas.ac.uk/met/READER/data. ERAI and ERA5 data are from ECMWF (https://apps.ecmwf.int/ datasets/). JRA-55 and CFSR data are obtained from the National Center for Atmospheric Research (NCAR) of the United States (http://rda.ucar.edu/datasets/). MERRA-2 data are available at https:/gmao.gsfc.nasa.gov/reanalysis/ MERRA-2/.

\section{REFERENCES}

Abernathey, R. P., I. Cerovecki, P. R. Holland, E. Newsom, M. Mazloff, and L. D. Talley, 2016: Water-mass transformation by sea ice in the upper branch of the Southern Ocean overturning. Nat. Geosci., 9, 596-601, https://doi.org/10.1038/ ngeo2749.

Bracegirdle, T. J., 2013: Climatology and recent increase of westerly winds over the Amundsen Sea derived from six reanalyses. Int. J. Climatol., 33, 843-851, https://doi.org/10.1002/ joc.3473.

_- , and G. Marshall, 2012: The reliability of Antarctic tropospheric pressure and temperature in the latest global reanalyses. J. Climate, 25, 7138-7146, https://doi.org/10.1175/ JCLI-D-11-00685.1.

Das, I., and Coauthors, 2013: Influence of persistent wind scour on the surface mass balance of Antarctica. Nat. Geosci., 6, 367371, https://doi.org/10.1038/ngeo1766.

Dee, D. P., and Coauthors, 2011: The ERA-Interim reanalysis: Configuration and performance of the data assimilation system. Quart. J. Roy. Meteor. Soc., 137, 553-597, https://doi.org/ 10.1002/qj.828.

Gelaro, R., and Coauthors, 2017: The Modern-Era Retrospective Analysis for Research and Applications, version 2 (MERRA-2). J. Climate, 30, 5419-5454, https://doi.org/10.1175/JCLI-D-160758.1 .

Grazioli, J., J. B. Madeleine, H. Gallée, R. M. Forbes, C. Genthon, G. Krinner, and A. Berne, 2017: Katabatic winds diminish precipitation contribution to the Antarctic ice mass balance. Proc. Natl. Acad. Sci. USA, 114, 10 858-10 863, https://doi.org/ 10.1073/pnas.1707633114.

Hazel, J. E., and A. L. Stewart, 2019: Are the near-Antarctic easterly winds weakening in response to enhancement of the southern annular mode? J. Climate, 32, 1895-1918, https:// doi.org/10.1175/JCLI-D-18-0402.1.

Helfand, H. M., and S. D. Schubert, 1995: Climatology of the simulated Great Plains low-level jet and its contribution to the continental moisture budget of the United States. J. Climate, 8, 784-806, https://doi.org/10.1175/1520-0442(1995) $008<0784$ :COTSGP $>2.0$. CO 2 .

Hennermann, K., and A. Guillory, 2019: What are the changes from ERA-Interim to ERA5? ECMWF, https://confluence.ecmwf.int/ pages/viewpage. action?pageId $=74764925$.

Hersbach, H., and D. Dee, 2016: ERA5 reanalysis is in production. ECMWF Newsletter, No. 147, ECMWF, Reading, United Kingdom, 7, http://www.ecmwf.int/sites/default/files/elibrary/ 2016/16299-newsletter-no147-spring-2016.pdf.

Huai, B., Y. Wang, M. Ding, J. Zhang, and X. Dong, 2019: An assessment of recent global atmospheric reanalyses for Antarctic near surface air temperature. Atmos. Res., 226, 181-191, https://doi.org/10.1016/j.atmosres.2019.04.029.

Jones, R. W., I. A. Renfrew, A. Orr, B. G. M. Webber, D. M. Holland, and M. A. Lazzara, 2016: Evaluation of four global reanalysis products using in situ observations in the Amundsen Sea Embayment, Antarctica. J. Geophys. Res. Atmos., 121, 6240-6257, https://doi.org/10.1002/2015JD024680.

Kanamitsu, M., W. Ebisuzaki, J. Woollen, S.-K. Yang, J. J. Hnilo, M. Fiorino, and G. L. Potter, 2002: NCEP-DOE AMIP-II Reanalysis (R-2). Bull. Amer. Meteor. Soc., 83, 1631-1644, https://doi.org/10.1175/BAMS-83-11-1631.

King, J. C., and J. Turner, 2007: Antarctic Meteorology and Climatology. Cambridge University Press, 424 pp.

— - and Coauthors, 2017: The impact of föhn winds on surface energy balance during the 2010-2011 melt season over Larsen C Ice Shelf, Antarctica. J. Geophys. Res. Atmos., 122, $12062-$ 12 076, https://doi.org/10.1002/2017JD026809.

Kobayashi, S., and Coauthors, 2015: The JRA-55 reanalysis: General specifications and basic characteristics. J. Meteor. Soc. Japan, 93, 5-48, https://doi.org/10.2151/jmsj.2015-001.

Lazzara, M. A., G. A. Weidner, L. M. Keller, J. E. Thom, and J. J. Cassano, 2012: Antarctic automatic weather station program: 30 years of polar observations. Bull. Amer. Meteor. Soc., 93, 1519-1537, https://doi.org/10.1175/BAMS-D-11-00015.1.

Lenaerts, J. T. M., and Coauthors, 2017: Meltwater produced by wind-albedo interaction stored in an East Antarctic ice shelf. Nat. Climate Change, 7, 58-62, https://doi.org/10.1038/ nclimate 3180.

Long, C. S., M. Fujiwara, S. Davis, D. M. Mitchell, and C. J. Wright, 2017: Climatology and interannual variability of dynamic variables in multiple reanalyses evaluated by the SPARC Reanalysis Intercomparison Project (S-RIP). Atmos. Chem. Phys., 17, 14 593-14 629, https://doi.org/10.5194/acp-17-14593-2017.

Marshall, G. J., 2003: Trends in the southern annular mode from observations and reanalyses. J. Climate, 16, 4134-4143, https:// doi.org/10.1175/1520-0442(2003)016<4134:TITSAM>2.0.CO;2.

Molod, A. M., L. L. Takacs, M. J. Suarez, and J. Bacmeister, 2015: Development of the GEOS-5 atmospheric general circulation model: Evolution from MERRA to MERRA2. Geosci. Model Dev., 8, 1339-1356, https://doi.org/10.5194/gmd-8-1339-2015.

Nygård, T., and Coauthors, 2016: Validation of eight atmospheric reanalyses in the Antarctic Peninsula region. Quart. J. Roy. Meteor. Soc., 142, 684-692, https://doi.org/10.1002/qj.2691.

Parish, T. R., and J. J. Cassano, 2003: The role of katabatic winds on the Antarctic surface wind regime. Mon. Wea. Rev., 131, 317-333, https://doi.org/10.1175/1520-0493(2003) $131<0317$ :TROKWO $>2.0$. CO; . 
_, and D. H. Bromwich, 2007: Re-examination of the nearsurface air flow over the Antarctic continent and implications on atmospheric circulations at high southern latitudes. Mon. Wea. Rev., 135, 1961-1973, https://doi.org/10.1175/MWR3374.1.

Paulson, C. A., 1970: The mathematical representation of wind speed and temperature profiles in the unstable atmospheric surface layer. J. Appl. Meteor., 9, 857-861, https://doi.org/ 10.1175/1520-0450(1970)009<0857:TMROWS > 2.0.CO;2.

Périard, C., and P. Pettré, 1993: Some aspects of the climatology of Dumont D'Irville, Adélie Land, Antarctica. Int. J. Climatol., 13, 313-328. https://doi.org/10.1002/joc.3370130307.

Pryor, S. C., and Coauthors, 2009: Wind speed trends over the contiguous United States. J. Geophys. Res., 114, D14105, https://doi.org/10.1029/2008JD011416.

Rodrigo, J. S., J.-M. Buchlin, J. van Beeck, J. T. M. Lenaerts, and M. R. van den Broeke, 2013: Evaluation of the Antarctic surface wind climate from ERA reanalyses and RACMO2/ANT simulations based on automatic weather stations. Climate Dyn., $\mathbf{4 0}$, 353-376, https://doi.org/10.1007/s00382-012-1396-y.

Saha, S., and Coauthors, 2010: The NCEP Climate Forecast System Reanalysis. Bull. Amer. Meteor. Soc., 91, 1015-1057, https:// doi.org/10.1175/2010BAMS3001.1.

— , and Coauthors, 2014: The NCEP Climate Forecast System version 2. J. Climate, 27, 2185-2208, https://doi.org/10.1175/ JCLI-D-12-00823.1.

Sanz Rodrigo, J., 2011: On Antarctic wind engineering. Ph.D. thesis, Université Libre de Bruxelles, 218 pp.

Tetzner, D., E. Thomas, and C. Allen, 2019: A validation of ERA5 reanalysis data in the southern Antarctic Peninsula-Ellsworth Land region, and its implications for ice core studies. Geosciences, 9, 289, https://doi.org/10.3390/geosciences9070289.

Thompson, D. W. J., and S. Solomon, 2002: Interpretation of recent Southern Hemisphere climate change. Science, 296, 895-899, https://doi.org/10.1126/science.1069270.
Torralba, V., F. J. Doblas-Reyes, and N. Gonzalez-Reviriego, 2017: Uncertainty in recent near-surface wind speed trends: A global reanalysis intercomparison. Environ. Res. Lett., 12, 114019, https://doi.org/10.1088/1748-9326/aa8a58.

Turner, J., and Coauthors, 2004: The SCAR READER Project: Toward a high-quality database of mean Antarctic meteorological observations. J. Climate, 17, 2890-2898, https://doi.org/ 10.1175/1520-0442(2004)017<2890:TSRPTA > 2.0.CO;2.

_, S. N. Chenoli, A. Abu Samah, G. Marshall, T. Phillips, and A. Orr, 2009: Strong wind events in the Antarctic. J. Geophys. Res., 114, D18103, https://doi.org/10.1029/2008JD011642.

Turton, J. V., A. Kirchgaessner, A. N. Ross, and J. C. King, 2018: The spatial distribution and temporal variability of föhn winds over the Larsen C ice shelf, Antarctica. Quart. J. Roy. Meteor. Soc., 144, 1169-1178, https://doi.org/10.1002/qj.3284.

van den Broeke, M. R., and N. P. M. van Lipzig, 2003: Factors controlling the near-surface wind field in Antarctica. Mon. Wea. Rev., 131, 733-743, https://doi.org/10.1175/1520-0493(2003) $131<0733$ :FCTNSW $>2.0 . \mathrm{CO} ; 2$.

Wang, Y., and Coauthors, 2016: A comparison of Antarctic Ice Sheet surface mass balance from atmospheric climate models and in situ observations. J. Climate, 29, 5317-5337, https:// doi.org/10.1175/JCLI-D-15-0642.1.

Yasunari, T., and S. Kodama, 1993: Intraseasonal variability of katabatic wind over East Antarctica and planetary flow regime in the Southern Hemisphere. J. Geophys. Res., 98, 13063 13 070, https://doi.org/10.1029/92JD02084.

Yu, L. J., and S. Y. Zhong, 2019: Strong wind speed events over Antarctica and its surrounding oceans. J. Climate, 32, 34513470, https://doi.org/10.1175/JCLI-D-18-0831.1.

Zhang, Y., Y. Wang, B. Huai, M. Ding, and W. Sun, 2018: Skill of the two 20th century reanalyses in representing Antarctic near-surface air temperature. Int. J. Climatol., 38, 4225-4238, https://doi.org/10.1002/joc.5563. 